\title{
A DIVERSIDADE CULTURAL NA FORMAÇÃO E ATUAÇÃO DE PROFESSORES
}

\author{
Cultural diversity in the training and conduct of teachers
}

La diversidad cultural en la formación y la actuación de profesores

Vera Lúcia Messias Fialho Capellini ${ }^{1}$

Janaina de Oliveira Macena ${ }^{2}$

\begin{abstract}
Resumo
O presente artigo discorre sobre dados levantados a partir de uma pesquisa de mestrado que abordou a diversidade cultural no contexto educacional por meio do relato de professores. Apresentamos neste momento a análise dos resultados obtidos dos professores da rede pública do ensino fundamental $-1 .^{\circ}$ ao $5 .^{\circ}$ ano do Estado de São Paulo de uma cidade interiorana de médio porte. O estudo teve como objetivo investigar a presença da diversidade cultural na formação e atuação docente, a partir do relato dos próprios professores diante da aplicação de um questionário desenvolvido pelas pesquisadoras. Como embasamento teórico para o entendimento de cultura, assumiramse os Estudos Culturais, a partir de Hall (1997). Para o entendimento da interculturalidade no ambiente escolar estabelecemos como pilares Fleuri (2003), Candau (2005) e Silva (2003). Os resultados alcançados apontam a necessidade de formação mais consistente e continuada aos professores, não somente no aspecto profissional, mas também no pessoal. Concluímos ser esse um campo propício para o desenvolvimento de outros estudos que contribuam para consolidar espaços de formação profissional de professores capacitados a promover e praticar o respeito às diferenças, garantindo, assim, o atendimento e a inclusão ativa da diversidade em ambiente escolar.
\end{abstract}

PALAVRAS-CHAVE: Diversidade cultural. Formação de professores. Atuação de professores.

\begin{abstract}
This paper is about data raised from a master's degree research on cultural diversity in the context of education through reports by teachers. We present at this moment the analysis of the results obtained from teachers of public primary schools $-1^{\text {st }}$ to $5^{\text {th }}$ grade in a medium-sized town in the State of São Paulo. The study aimed to investigate the presence of cultural diversity in the training and conduct of teachers, from their own reports, based on the application of a questionnaire developed by the researchers. As the theoretical standpoint for the understanding of culture, Hall's (1997) Cultural Studies were adopted. For the understanding of interculturality in school settings we established as pillars Fleuri (2003), Candau (2005) and Silva (2003). The results obtained point to the necessity of a more consistent and continued training of teachers, not only in the professional aspect, but also in the personal one. We conclude that this is a field

\footnotetext{
${ }^{1}$ Doutorado em Educação Especial. Mestrado em Educação Especial (Educação do Indivíduo Especial) Universidade Federal de São Carlos, UFSCAR, Brasil. Professora Assistente - Departamento de Educação - Universidade Estadual Paulista (UNESP) - Câmpus de Bauru - São Paulo - Brasil. Email: verinha@fc.unesp.br

${ }^{2}$ Mestrado- Universidade Estadual Paulista. Faculdade de Ciências, Bauru.
} 
favourable to the development of other studies that may contribute to consolidate spaces of professional training of teachers who are able to promote and to practice the respect for differences, guaranteeing, therefore, the consideration and active inclusion of diversity in school settings.

KEYWORDS: Cultural diversity. Teachers' training. Teachers' conduct.

\section{Resumen}

El presente artículo discurre sobre datos obtenidos a partir de una investigación de maestría que abordó la diversidad cultural en el contexto educacional a través del relato de profesores. Presentamos en este momento el análisis de los resultados obtenidos con los profesores de escuelas públicas de educación primaria $-1 .^{\circ}$ a $5 .^{\circ}$ curso de una ciudad media del Estado de São Paulo. El estudio tuvo como objetivo investigar la presencia de la diversidad cultural en la formación y la actuación docente, a partir del relato de los propios profesores con la aplicación de un cuestionario desarrollado por las investigadoras. Como base teórica para el entendimiento de cultura se asumieron los Estudios Culturales, a partir de Hall (1997). Para el entendimiento de la interculturalidad en el ambiente escolar establecemos como pilares Fleuri (2003), Candau (2005) y Silva (2003). Los resultados obtenidos señalan la necesidad de formación más consistente y continua de los profesores, no sólo en el aspecto profesional, sino también en el personal. Concluimos ser este un campo propicio para el desarrollo de otros estudios que contribuyan para consolidar espacios de formación profesional de profesionales capacitados para promover y practicar el respeto a las diferencias, garantizando así, la atención y la inclusión activa de la diversidad en ambiente escolar.

PALABRAS CLAVE: Diversidad cultural. Formación de profesores. Actuación de profesores.

\section{INTRODUÇÃO}

O século XXI tem registrado como uma de suas marcas a presença maciça de discussões sobre a diferença entre as pessoas e como o reconhecimento dessas diferenças configura a existência da diversidade em nossa sociedade. Ao debatermos sobre as diferenças e as particularidades de cada um, estamos discutindo principalmente a cultura da qual esses sujeitos compartilham e como estes se relacionam.

O termo cultura ao longo do tempo tem assumido diferentes significados, adjetivações e flexões, além de ser estudado em diversas áreas das ciências humanas, sendo definida por estas a partir do seu objeto de estudo e olhar de mundo. Neste novo milênio, já nos acostumamos a ouvir a palavra cultura com os prefixos pluri/multi/inter/trans e com o sufixo "dade" (SOUZA, 2002). O sufixo "dade", de acordo com a língua portuguesa, transforma um adjetivo em um substantivo abstrato. Analisando os prefixos, temos "pluri", que vem do latim e significa muitos, vários; "multi”, também de origem latina, tem um conceito muito próximo, sendo sinônimo de múltiplo, numeroso. Já os sufixos “inter" e "trans" são de origem latina e significam 
respectivamente posição intermediária e sinônimo de entre; o "trans" assume a noção de movimento, ou seja, movimento para além, através.

Esse vasto espectro tem sido espaço de eloquentes interesses e discussões, dada a centralidade alcançada pela cultura nas mais variadas esferas da vida cotidiana. Godoy e Santos (2014) pontuam essa centralidade não como uma superioridade às demais dimensões sociais, mas como uma transversalidade, ou seja, a capacidade de a cultura estar presente em toda e qualquer prática social. Essa centralidade seria "a forma como a cultura penetra em cada recanto da vida social contemporânea, fazendo proliferar ambientes secundários, mediando tudo" (HALL, 1997, p. 5). A cultura, portanto, é parte constituinte das práticas sociais e precisa ser observada a partir de seus significados e das relações que estabelece no ambiente. Se essa relação é hierárquica, observamos uma sociedade em que a presença do preconceito é inevitável.

Como afirma Sodré (2005, p. 9, grifo do autor):

[...] cultura é uma dessas palavras metafóricas (como, por exemplo, liberdade) que deslizam de um contexto para outro, com significações diversas. É justamente esse "passe livre" conceitual que universaliza discursivamente o termo, fazendo de sua significação social a classe de todos os significados. A partir dessa operação, cultura passa a demarcar fronteiras, a estabelecer categorias de pensamento, a justificar as mais diversas ações e atitudes, a instaurar doutrinariamente o racismo e a se substancializar, ocultando a arbitrariedade histórica de sua invenção.

Considerar a cultura por esse olhar é posicioná-la como elemento aberto a evidenciar as diferenças comportamentais individuais e como substrato para conciliar categorizações coletivas, o que nos coloca a necessidade de também superar estereótipos e desenvolver meios interativos dos quais diversas culturas possam compartilhar. Conforme nos aponta Fleuri (2003, p. 24):

Quando as diferenças culturais são consideradas numa perspectiva estereotipada, focaliza-se apenas as manifestações externas e particulares dos fenômenos culturais. Deixa-se de valorizar devidamente os sujeitos sociais que produzem tais manifestações culturais, ou não se consegue compreender a densidade, a dinamicidade e a complexidade dos significados que eles tecem.

Foi justamente a falta de entendimento sobre a complexidade de determinados fenômenos ao longo da história que provocou a inserção de questões culturais nos debates contemporâneos, especialmente no ambiente escolar, tendo ponto de partida nas questões de raça e na discussão dos direitos humanos entre as décadas de 1970 e 1980, o que significa que observar como essa discussão se instaura nas práticas educativas representa 
olhar para as práticas sociais no decorrer do tempo. A importância dessa pauta "reafirma a centralidade da educação como processo e da escola como instituição social no enquadramento e/ou mediação dos dilemas colocados à sociedade" (RODRIGUES; ABRAMOWICZ, 2011, p. 246).

A partir da década de 1980, surgem várias reinvindicações por meio de movimentos sociais organizados em busca de garantia de seus direitos. A visibilidade social a partir dessa década dos diversos recortes dentro da ampla temática da diversidade cultural (negros, índios, mulheres, pessoas com deficiência, homossexuais, entre outros), segundo Gomes (2003, p. 72), "coloca-nos diante da luta desses e outros grupos em prol do respeito à diferença”.

Respondendo a esse contexto, o enfoque da cultura anteriormente tida como a produção e acesso às Belas Artes e ao domínio da História da Arte, ambos privilégios de uma classe social com acesso à Educação, amplia-se para o reconhecimento dos diversos saberes populares com as declaradas diferenças entre esses saberes. Esse enfoque carrega em si a luta pela garantia de direitos de grupos sociais específicos, organizados em torno de determinadas características em comum, que os diferenciam de outros grupos. Portanto, vê-se a tomada da cultura como campo fértil para tratar as questões das diferenças e das desigualdades, sem que ambas se anulem. De fato, "a igualdade não está oposta à diferença, e sim à desigualdade, e diferença não se opõe à igualdade, e sim à padronização, à produção em série, à uniformização" (CANDAU, 2012, p. 239). Essa padronização que resulta em uma produção em série é exatamente o que gostaríamos de ver superado nas escolas, espaço que deve ser propício à expressão de saberes diversificados.

\section{A interculturalidade como articuladora de identidades culturais}

A dificuldade de entender o entrelaçamento entre as diversas terminologias é ponto indubitavelmente presente nas discussões dos conceitos relacionados à cultura, assim como o questionamento sobre a necessidade ou não de se determinar uma terminologia única (CANEN, 2000; CANDAU, 2002a, 2009; FLEURI, 2003). Para Fleuri (2003, p. 17), "tais embaraçamentos entre as perspectivas impedem-nos de produzir esquemas simplificatórios eficazes, mas tornam o debate criativo e aberto ao aprofundamento". 
A partir do século XX é crescente o número de estudos que discutem as perspectivas de análise relacionadas à diversidade cultural, em especial no meio escolar, e referem-se a variadas maneiras de interpretar como se dá a interação entre grupos sociais e suas culturas, principalmente no sentido de discutir conceitualmente os termos correlatos à diversidade cultural, como o multiculturalismo, a interculturalidade e a pluralidade cultural (MCLAREN, 1997; GONÇALVES; SILVA, 1998; CANDAU; ANHORN, 2000; FLEURI, 2003; GOMES, 2003; PADILHA, 2004; CORSI, 2007; CANDAU; RUSSO, 2010; SILVA, 2014).

Todos esses conceitos nos conduzem a debates sobre identidade e sua relação com a diversidade e a diferença. Para iniciar uma discussão sobre identidade trar-se-á o termo de antemão, no plural e combinado com o termo cultural, dimensão humana que é nosso foco neste estudo. As identidades culturais, segundo Fleuri (2003, p. 23), "são aqueles aspectos de nossas identidades que surgem de nosso pertencimento a culturas étnicas, raciais, linguísticas, religiosas, nacionais e que sofrem contínuos deslocamentos ou descontinuidades".

O deslocamento das nossas identidades, ou seja, a capacidade de nos identificarmos com diferentes grupos e/ou estilo de vida e de outras pessoas produz uma variedade de possibilidades, gerando inúmeros grupos, cada qual com características específicas e particularidades que reivindicam respeito e espaço no cenário social ao longo da história. Souza (2002, p. 73), considera que “em cada um de nós, há identificações contraditórias que nos empurram em diferentes direções, de tal modo que nossas identidades estão sendo continuamente deslocadas".

Ao discutirmos a relação entre a(s) identidade(s) dos sujeitos, deparamo-nos com a diversidade que as reúne e com as diferenças que as personalizam. Os conceitos de diversidade e diferença muitas vezes aparecem na literatura com o mesmo sentido e conotação, porém, como nos afirmam Abramowicz, Rodrigues e Cruz (2011, p. 91), “em alguns momentos falamos em diversidade, outros em diferença e não são coisas iguais, nem mesmo próximas, apesar de que temos usado as palavras de maneira indiferenciada".

Para Candau (2011, p. 241), as diferenças culturais são "étnicas, de gênero, orientação sexual, religiosas, entre outras, e se manifestam em todas as suas cores, sons, ritos, saberes, sabores, crenças e outros modos de expressão”. A autora considera que são múltiplas as questões colocadas em torno das diferenças, e os movimentos sociais são os 
principais reivindicadores de igualdade de acesso, denunciando injustiças, desigualdades e discriminações e buscando reconhecimento político e social.

A diversidade cultural é definida como uma das principais preocupações sociais, relacionada ao crescimento de uma variedade de códigos sociais, dentro e entre sociedades. Como atesta o documento "Informe Mundial, investir na diversidade cultural e no diálogo intercultural" (UNESCO, 2010), é cada vez mais evidente que estilos de vida, representações sociais, sistemas de valores, códigos de conduta, relações sociais, formas linguísticas, processos cognitivos, expressões artísticas, noções de espaço público e privado, modos de comunicação e sistemas de pensamento não podem ser reduzidos a um modelo singular ou concebidos em termos de representações fixas. Todos esses componentes assentam-se sob o manto da diversidade cultural a partir do momento em que a sociedade gradativamente assume a existência de diversos modelos de ser humano e modos de vida. Isso se torna possível na medida em que tais questões passam a fazer parte da agenda política mundial e ter espaço de representatividade, como pontuam Rodrigues e Abramowicz (2011, p. 248).

A emergência política de comunidades locais, grupos indígenas, grupos
vulneráveis e excluídos por sua origem étnica, idade ou gênero tem levado à
descoberta dentro de sociedades de novas formas de diversidade, e a
diversidade cultural tem tomado a agenda política de muitos países do mundo.

A crescente observação sobre o tema tem proporcionado espaço para que cada vez mais identidades, antes invisíveis, sejam reconhecidas e tenham sua cultura representada no cenário político e social.

Diante do exposto, acreditamos que a interculturalidade tenha muito a contribuir para a organização dessas relações. A perspectiva intercultural na visão de Candau (2005) objetiva a promoção de relações dialógicas e igualitárias entre pessoas e grupos culturais diferentes e tenta sempre trabalhar com os conflitos que emergem dessa convivência, sem ignorar as relações de poder existentes.

O estudo da origem da interculturalidade, segundo Fleuri (2003), leva-nos ao cenário europeu, em que inicialmente foi vista como solução para a inclusão de imigrantes na educação em caráter emergencial. Progressivamente avançada para a valorização das diferenças, a formação da identidade e a legitimação da cultura de origem de cada indivíduo, essa perspectiva proporciona não somente o fortalecimento da identidade, 
como também reconhece importância em considerar o contexto no qual o aluno encontrase inserido.

\begin{abstract}
A noção de interculturalidade, além de expressar a coesão étnica de um grupo social, proporcionando condições para o fortalecimento da identidade cultural, vai também estimular a aquisição do conhecimento cultural de outros povos. Isto significa uma mudança no tratamento da pluriculturalidade no espaço da escola. Das preocupações marcadamente linguísticas, características da educação bicultural e bilíngue, a interculturalidade considera o contexto sociocultural dos alunos (SILVA, 2003, p. 41-42).
\end{abstract}

Analogamente a Silva (2003), Barros e Kauark (2011) acrescentam que nessa perspectiva uma educação para a diversidade cultural deixaria de ser pensada no limite de uma educação para a tolerância, transformando-se na educação para uma sociedade pluralista. Aqui, o papel da educação deixaria de ser a formalização de um conjunto de condutas aceitas, transformando-se em processo de mediação entre as diferenças.

Para tanto, alguns desafios devem ser enfrentados na promoção de uma educação intercultural. Candau (2002b, 2005) ressalta ser preciso penetrar no universo de preconceitos e discriminações presentes na sociedade brasileira, articular igualdade e diferença no nível das políticas educativas, promover experiências de interação sistemática com outros e reconstruir os processos de construção das nossas identidades culturais, tanto no âmbito mundial, pessoal, quanto no coletivo.

Diante do exposto, pontuamos que interculturalidade é então concebida como "uma estratégia ética, política e epistêmica" (CANDAU; RUSSO, 2010, p. 166) orientada à construção de uma "sociedade democrática, plural, humana, que articule políticas de igualdade com políticas de identidade" (CANDAU, 2009, p. 78).

No âmbito das ações docentes, essa perspectiva inclui processos interativos em sala de aula, requerendo participação dialógica e dinâmica, entendendo os conflitos como mobilizadores de processos de aprendizagem, com negociação entre os estudantes mediados pelos docentes, em que os conhecimentos podem ser compartilhados e as dificuldades individuais superadas.

Fleuri (2003) chama-nos a atenção para outro aspecto relevante quando discorremos sobre o professor: seu posicionamento como indivíduo. Isso significa pensar sobre:

[...] as formas e os conteúdos da cultura interiorizada pelos indivíduos na vida cotidiana, a variedade dos canais e das experiências com que estabelecem contato de acordo com sua posição social, as sínteses de modelos - 
frequentemente contraditórios - que vão elaborando no decurso da própria vida. Nessa direção, aparece como questão central na prática pedagógica a visão de mundo dos sujeitos em formação, assim como a relação entre tal visão e os modelos (de conhecimento, de avaliação, de comportamento) transmitidos através de situações educativas, particularmente na escola (FLEURI, 2003, p. 20).

Cumpre salientar, portanto, que ações orientadas pelos professores e outros agentes escolares que considerem ou não a diversidade, refletem-nos como sujeitos e servem como modelo aos alunos, sujeitos em formação. Assim, tais profissionais devem levar em conta que o currículo nos transforma e somos transformadores do currículo, como colocado por Silva (1995), da mesma forma que somos também transformados pelas outras tantas experiências que vivemos. Estarmos atento ao sujeito que somos é estarmos comprometidos com a própria formação e com a dos alunos, pois como educadores devemos assumir nosso papel como modelo. “[...] o currículo é muito mais do que uma questão cognitiva, é muito mais que construção do conhecimento, no sentido psicológico. O currículo é a construção de nós mesmos como sujeitos” (SILVA, 1995, p. 196).

Nesse ponto, reitera-se a importância do envolvimento, autonomia e capacitação dos professores e atores presentes no cenário escolar, para que a diversidade cultural represente um tema com menos entraves e, principalmente, seja encarada como força motriz no desenvolvimento de estratégias pedagógicas e de convívio social na prática de currículos que colaborem ativamente para uma educação considerada inclusiva, que resulte na formação de sujeitos críticos.

Essa é a postura que gostaríamos de encontrar nas ações dos sujeitos, foco da pesquisa. Professores autônomos, capazes de desenvolver estratégias pedagógicas, que promovam uma prática reconhecedora da diversidade e ativa na produção de uma educação inclusiva, emancipadora. Para tanto, pontuamos neste relato o objetivo de analisar a opinião dos professores sobre sua formação e atuação quanto às temáticas da diversidade cultural e sobre sua frequência em ambientes culturais, o que esperamos refletir em determinada medida a formação do professor enquanto sujeito.

\section{Esclarecendo os dados encontrados}

A pesquisa contou com dois momentos de coleta de dados (MACENA, 2017). Restringir-nos-emos a apresentar os dados da segunda parte da pesquisa em que um 
questionário elaborado pelas próprias pesquisadoras com base na literatura foi aplicado aos sujeitos participantes.

Participaram da pesquisa 441 professores da rede pública estadual dos anos iniciais do ensino fundamental $-1 .^{\circ}$ ao 5..$^{\circ}$ ano, dos quais 295 apresentaram devolutiva, produzindo $67 \%$ de respostas referentes a 27 escolas de uma cidade de médio porte do Estado de São Paulo. A análise dos resultados dos questionários com questões de múltipla escolha aplicados aos professores teve como meta estabelecer uma caracterização do participante, sua formação (acadêmica e pessoal), sua prática docente e seu conhecimento sobre o tema tratado, e os dados foram apresentados por meio da frequência absoluta de respostas obtidas. Os dados concernentes à caracterização dos participantes quanto à idade mostram que 94,5\% dos professores consultados possuem mais que 30 anos, e destes quase $30 \%$ possuem mais que 50 anos. A população abaixo de 30 anos representa em torno de $5 \%$ e apenas $0,4 \%$ não respondeu à questão.

Desses professores $10,5 \%$ são formados no magistério, ou têm ensino superior incompleto, $38 \%$ cursaram pós-graduação e 50,2\% deles declararam ensino superior completo. Um por cento dos participantes não respondeu a essa questão. Observou-se que $60,7 \%$ trabalha na rede pública de ensino há mais de dez anos, dos quais $28,8 \%$ está na rede há mais de 20 anos. Foi contabilizada uma taxa em torno de $4 \%$ de ausência de resposta a esse item. No tocante à docência, especificamente ao ensino fundamental ciclo I, em torno de 40\% declarou lecionar há menos de dez anos, 26\% leciona há mais de 20 anos e 5,8\% não respondeu à pergunta, restando em torno de $29 \%$ dos professores com tempo de licenciatura entre 10 e 20 anos.

Os dados a seguir são referentes aos espaços culturais frequentados pelos professores como expectadores. 
Gráfico 1: Percentual de respostas dos professores às perguntas sobre a própria formação e sobre a atuação profissional com relação à diversidade cultural

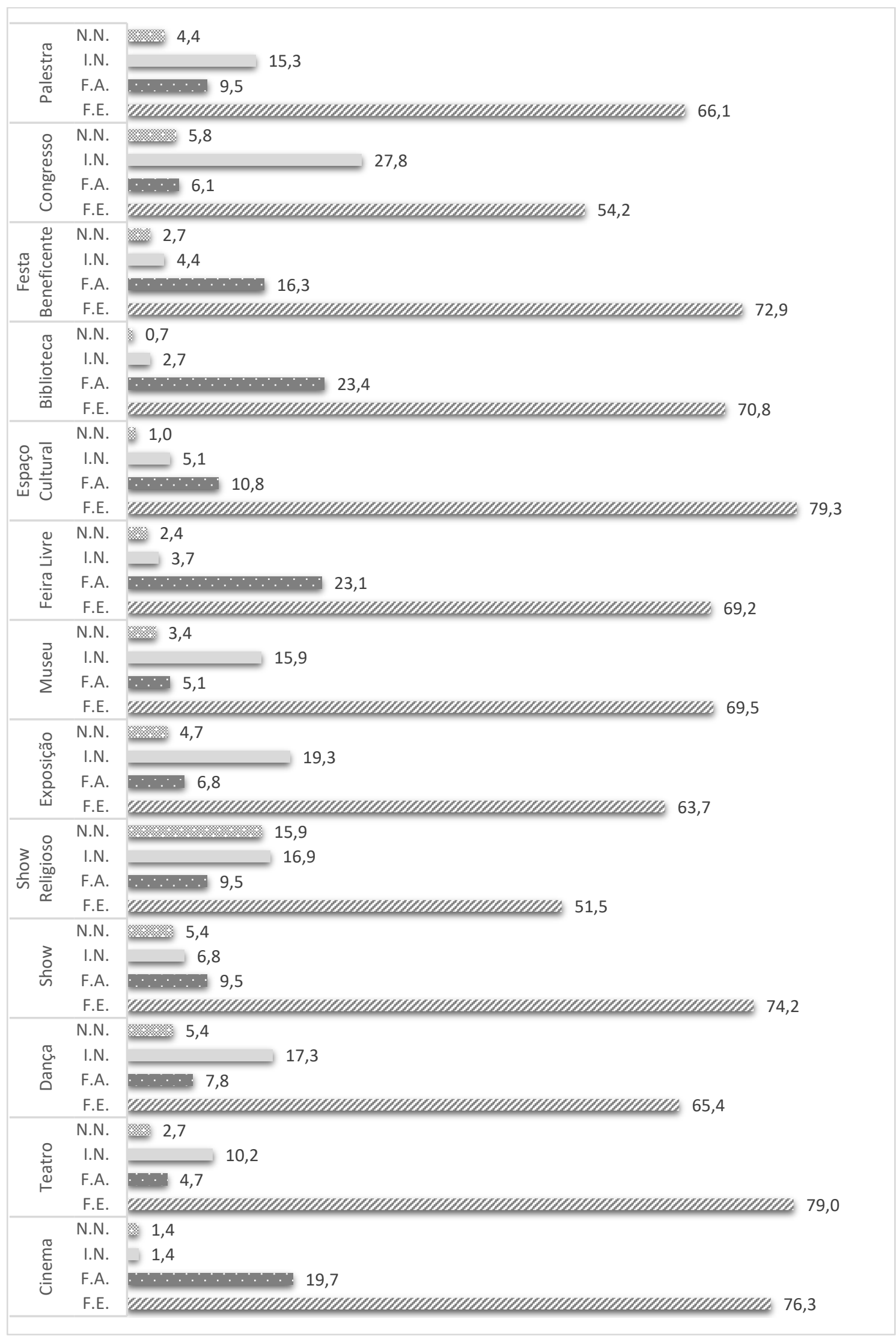


Fonte: Macena (2017). * N.N. - Nunca frequentei e não tenho interesse; I.N. - Tenho interesse, mas nunca frequentei; F.A. - Frequento assiduamente; F.E. - Frequento eventualmente.

Quanto à formação individual do sujeito, observamos a partir de Fleuri (2003) a importância do posicionamento pessoal do professor na vida social e decidimos por questionar o professor sobre sua frequência em locais considerados culturais, ou seja, em locais que socialmente são reputados como transmissores de saberes culturais e populares. A tabela representa a frequência de resposta dos professores, das quais torna-se relevante perceber que os únicos lugares com frequência assídua dos nossos participantes maior que $20 \%$ foram "feira livre" e "biblioteca". A primeira é um local de cultura popular que remete a atividades não somente culturais, mas também alimentares e a segunda é um espaço que quase todas as escolas possuem, ou seja, um local frequentado assiduamente por somente $20 \%$ dos participantes da pesquisa, mesmo sendo este um local agregado ao local de trabalho da maioria dos participantes. Os demais locais apresentaram índice menor que $20 \%$ de frequência assídua.

No tocante à a presença dos participantes em locais de expressão das vertentes artísticas, aparece em primeiro lugar o cinema como o mais frequentado assiduamente, seguido por shows e shows religiosos, e este último garante uma porcentagem de $60 \%$ de frequentadores entre assídua e eventualmente. Destaque também merecido para os aproximadamente $20 \%$ de não frequência a exposições e museus.

Outros dois índices interessantes são os quase $20 \%$ de respostas para nunca terem frequentado uma palestra e mais de $30 \%$ que nunca frequentaram um congresso. Esses dois dados são dignos de nota, visto que se trata de ambientes classicamente considerados como locais de aprendizagem e transmissão de conhecimento, o que nos conduz a sugerir que uma porcentagem significativa dos professores participantes dessa pesquisa está à margem de atualizações e formação continuada por esses meios.

A fim de compreendermos o que o participante da pesquisa considera por diversidade cultural, disponibilizamos quinze termos elencados a partir da literatura em uma lista em que o participante poderia assinalar mais do que um termo a partir do enunciado: "Quando penso em diversidade cultural penso em...”. Os resultados trazem em primeiro lugar uma relação entre diversidade cultural e religião, assinalada por quase 90\% dos participantes. Seguida por etnia e raça, gênero e sexualidade, além de classe social, categoria inserida na pesquisa dada a discrepância entre classes sociais existentes 
no Brasil, recebendo maior índice de respostas do que deficiência e direitos humanos, dois termos comumente relacionados à diversidade cultural.

Gráfico 2: Percentual de respostas dos professores à pergunta sobre o que pensam com relação à diversidade cultural

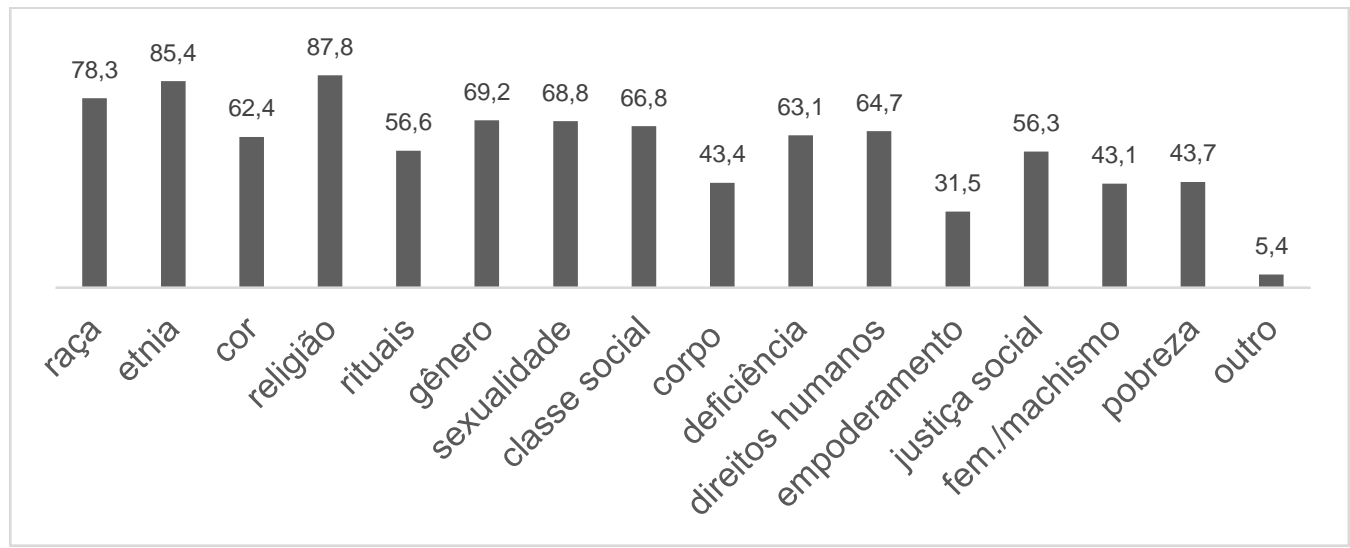

Fonte: Macena (2017). *E.P. - em partes

No que tange à formação acadêmica, 63,7\% dos professores responderam que foram instruídos durante sua formação sobre o tema diversidade cultural. A mesma porcentagem referiu-se aos professores que declararam ter feito algum curso específico sobre a temática, podendo explicar o índice da primeira questão, o que sugere que os professores possivelmente foram instruídos em cursos específicos sobre a temática, e não necessariamente em disciplinas fornecidas como obrigatórias na grade curricular da faculdade que cursaram.

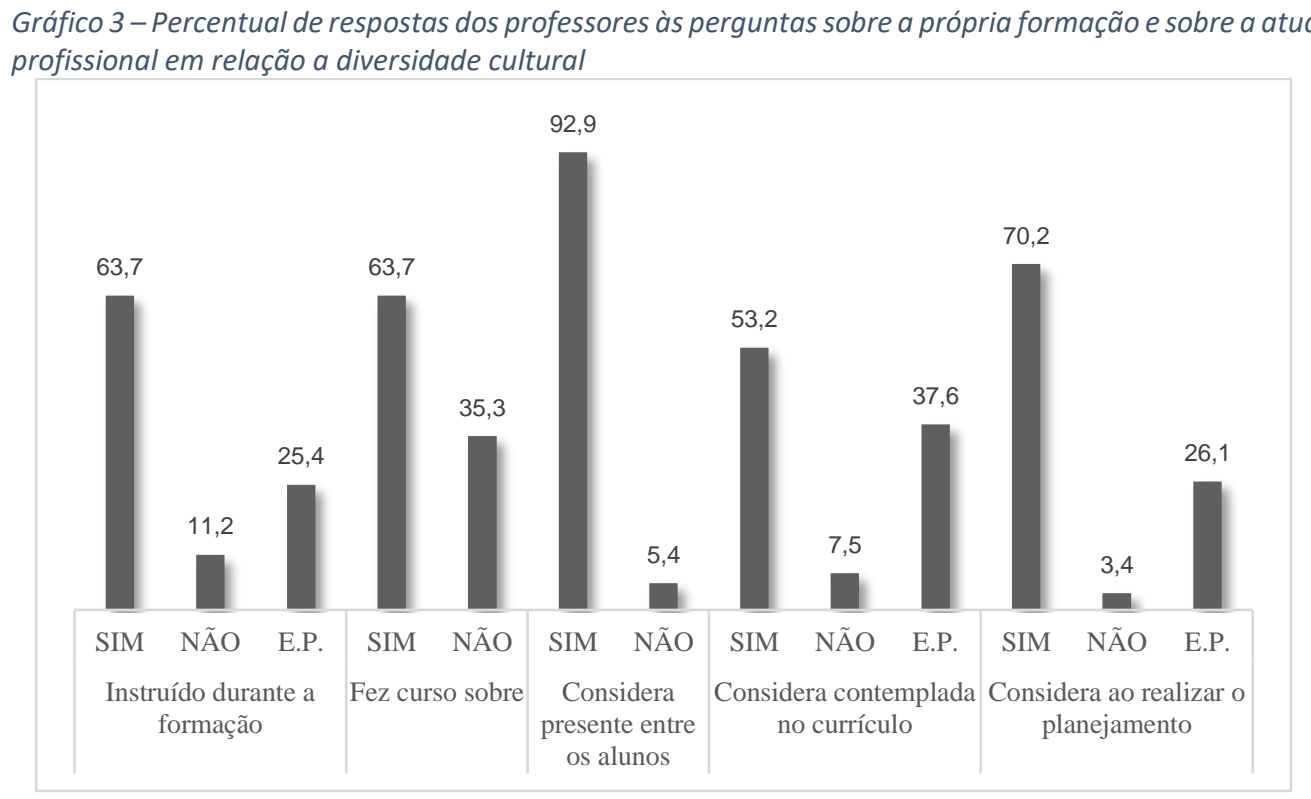

*E.P. - em partes 
Ao serem questionados sobre a presença da diversidade cultural entre seus alunos, 5,4\% consideraram que ela não está presente e 92,9\% responderam afirmativamente, sendo o restante de $1,7 \%$ destinado às pessoas que deixaram essa resposta em branco. Esse mesmo índice foi encontrado nas abstenções na pergunta seguinte, referente à contemplação da temática no currículo do Estado, tendo obtido $53,2 \%$ respostas afirmativas e $37,6 \%$ de respostas para "em parte". Os participantes da pesquisa afirmaram em $70,2 \%$ que as atividades propostas em sala de aula são fruto de um planejamento que leva em consideração a temática da diversidade cultural.

Sobre o material didático entregue pela secretaria de Estado às escolas, 93,9\% dos professores declaram utilizá-lo no planejamento de suas aulas. Desses professores, aproximadamente $50 \%$ consideram que o tema diversidade cultural é abordado de forma adequada no material, com 3,4\% de abstenção à questão. Dos professores $4 \%$ também se abstiveram de responder sobre a utilização de outros recursos didáticos; 3,4\% disseram que não usam e 92,5\% declararam fazer uso de outros recursos para o planejamento das aulas, além do material didático aqui tratado.

\section{CONSIDERAÇÕES FINAIS}

O estudo buscou analisar as relações contidas no relato dos professores sobre sua formação e sua prática do ponto de vista da diversidade cultural. O questionário produziu resultados capazes de fomentar novos interesses no campo científico na busca pela construção do saber relativamente às temáticas da diversidade.

A porcentagem de professores que consideram que a diversidade cultural está presente entre seus alunos é um dado bastante relevante, 92,9\% deles responderam que reconhecem a diversidade. Esse dado deixa claro que o professor está exposto à necessidade de lidar com as questões da diversidade cultural, porém os resultados apontam para a insuficiência do material didático ofertado em discutir tais questões, visto que pouco mais de $50 \%$ dos professores consideram que a diversidade está contemplada no currículo do Estado e somente 49,8\% dos professores acham que o guia utilizado para a formulação das aulas apresenta conteúdo adequado quanto à diversidade cultural. Esses mesmos professores responderam em 93,9\% que usam esse guia como fonte principal de consulta e, ao mesmo tempo, 70,2\% responderam que as atividades propostas em sala de aula são fruto de um planejamento que leva em conta a temática. Ou seja, se tomarmos 
os professores que dizem presenciar a diversidade em sala e os professores que afirmam considerar a temática no planejamento de suas aulas, existe uma diferença de aproximadamente $20 \%$ de professores que afirmam saber da diversidade em sala, mas que não a contemplam em seus planejamentos.

Ao considerarmos que $92,5 \%$ dos professores responderam que utilizam outros recursos didáticos para além daqueles presentes no currículo ofertado, podemos esperançar que tais recursos poderão ser úteis no desenvolvimento do nosso tema de estudo, apesar de não possuirmos recursos para afirmar tal coisa.

A discussão desses dados associados à formação dos participantes, ao tempo de magistério e à idade média que se apresentou, pode sugerir uma falta de atualização e uma rotina repetitiva, em razão do número de professores que responderam estar no mesmo ciclo e rede de ensino há mais de 10-20 anos, o baixo número de professores que declararam ter cursado pós-graduação e o alto índice de professores com mais de 50 anos. Consideramos esses dados insuficientes para afirmar tal relação, visto que não questionamos há quanto tempo esses sujeitos estão formados na graduação, o que talvez contribuísse para relacionar aos anos sem atualização do professor a dificuldade de lecionar, levando em conta a diversidade cultural no seu contexto. Acreditamos que essa seja uma boa sugestão de caminho para ampliação ou replicação da pesquisa.

Ficou evidente pelo relato dos professores a presença da diversidade cultural no currículo, porém bastante aquém do desejável para que a educação escolar seja considerada uma educação intercultural. Convém ressaltar que os temas mais citados por eles, ao fazerem referência à dificuldade de trabalho com a diversidade cultural, foram: "sexualidade", "gênero" e "religião". Tais temas foram registrados menos de cinco vezes na análise do material utilizado pelos professores, dados levantados na primeira parte da pesquisa complementar a esta, aqui relatada.

Tais dados nos sugerem que os professores não encontram respaldo nas orientações e nos materiais a eles conferidos, necessitando que estratégias sejam criadas e, acima de tudo, que o assunto seja mais intensamente debatido a fim de procurar caminhos para intervenção e transformação de seus alunos em sujeitos críticos e reflexivos. Assim, considerando os objetivos propostos, concluímos que a diversidade cultural está presente no currículo, mas de forma quase insignificante pelos parâmetros que apresenta. Igualmente, os professores encontram dificuldades no trabalho em sala de aula. 
Por fim, é imperativo pontuar que acreditamos que a perspectiva intercultural seja capaz, com relação às ações docentes e aos conteúdos escolares, de incentivar processos interativos em sala de aula, requerendo participação dialógica e dinâmica. Isso possibilita o entendimento de conflitos como mobilizadores de processos de aprendizagem, com negociação entre os estudantes mediados pelos docentes, criando condições para que os conhecimentos sejam aplicados e generalizados para outros contextos, outras situações da vida e fazendo, portanto, da escola um espaço para formação de sujeitos críticos.

\section{REFERÊNCIAS}

ABRAMOWICZ, A.; RODRIGUES, T. C.; CRUZ, A. C. J. da. A diferença e a diversidade na educação. Contemporânea - Revista de Sociologia da UFSCar, São Carlos, n. 2, p. 85-97, 2011.

BARROS, J. M.; KAUARK, G. (Org.). Diversidade cultural e desigualdade de trocas: participação, comércio e comunicação. São Paulo: Itaú Cultural, Observatório da Diversidade Cultural; PUCMinas, 2011.

BRASIL. Ministério da Educação. Parâmetros Curriculares Nacionais - Tema Transversal: pluralidade cultural. Brasília: MEC, 1998.

CANDAU, V. M. F. Sociedade, cotidiano escolar e cultura(s): uma aproximação. Educação \& Sociedade, Campinas, v. 23, n. 79, p. 125-161, ago. 2002a.

. Sociedade, educação e culturas: questões e propostas. Petrópolis: Vozes, $2002 \mathrm{~b}$. $\overline{\mathrm{DP} \& \mathrm{~A}}, 2005$.

(Org.). Cultura(s) e educação: entre o crítico e o pós-crítico. Rio de Janeiro:

Educação em direitos humanos e diferenças culturais: questões e buscas. Múltiplas Leituras, v. 2, n. 1, p. 65-82, jan.-jun. 2009.

Diferenças culturais, cotidiano escolar e práticas pedagógicas. Currículo sem fronteiras, v. 11, n. 2, p. 240-255, jul./dez. 2011.

Diferenças culturais, interculturalidade e educação em direitos humanos. Educação \& Sociedade, v. 33, n. 118, p. 235-250, 2012.

; ANHORN, C. T. G. A questão didática e a perspectiva multicultural: uma articulação necessária. In: REUNIÃO ANUAL DA ANPED, 23. 2000, Caxambu (MG). Anais... Caxambu (MG): Anped, 2000. 
; RUSSO, K. Interculturalidade e educação na América Latina: uma construção plural, original e complexa. Revista Diálogo Educacional, Curitiba, v. 10, n. 29, p. 151169, jan.-abr. 2010.

CANEN, A. Educação multicultural, identidade nacional e pluralidade cultural: tensões e implicações curriculares. Cadernos de Pesquisa, v. 111, p. 135-149, 2000.

CORSI, A. M. Currículo em ação nos anos iniciais do ensino fundamental e a atenção à multiculturalidade. 2007. 182 f. Tese (Doutorado em Ciências Humanas) - Universidade Federal de São Carlos, São Carlos, 2007.

FLEURI, R. M. Intercultura e educação. Revista Brasileira de Educação, Rio de Janeiro, n. 23, p. 16-35, ago. 2003.

GODOY, E. V.; SANTOS, V. M. Um olhar sobre a cultura. Educação em Revista, Belo Horizonte, v. 30, n.3, p.15-41, set. 2014.

GOMES, N. L. Educação e diversidade étnico-cultural. In: MINISTÉRIO DA EDUCAÇÃO. Diversidade na educação: reflexões e experiências. Brasília: Secretaria de Educação Média e Tecnológica, 2003. p. 67-76.

GONÇALVES, L. A. O.; SILVA, P. B. G. O jogo das diferenças: multiculturalismo e seus contextos. Belo Horizonte: Autêntica, 1998.

HALL, S. A centralidade da cultura: notas sobre as revoluções culturais do nosso tempo. Educação \& Realidade, v. 22, n. 2, p. 15-46, 1997. Disponível em: <http://www.seer.ufrgs.br/index.php/educacaoerealidade/article/view/71361/40514>. Acesso em: 2 fev. 2017.

MACENA, J. O. A diversidade cultural no currículo e na concepção de docentes: caminhos inclusivos em discussão. 2017. Dissertação (Mestrado em Psicologia do Desenvolvimento e Aprendizagem) - Faculdade de Ciências da Universidade Estadual Paulista (Unesp), Bauru.

MCLAREN, P. A vida nas escolas: uma introdução à pedagogia crítica nos fundamentos da educação. Porto Alegre: Artes Médicas, 1997.

MALANCHEN, J. A pedagogia histórico-crítica $e$ o currículo: para além do multiculturalismo das políticas curriculares nacionais. 2014. Tese (Doutorado em Educação Escolar) - Faculdade de Ciências e Letras da Universidade Estadual Paulista (Unesp), São Paulo.

PADILHA, P. R. Currículo intertranscultural: novos itinerários para a educação. São Paulo: Cortez, 2004.

RODRIGUES, T. C.; ABRAMOWICZ, A. Diversidade e as políticas públicas de educação. Revista Contrapontos, Itajaí, v. 11, n. 3, p. 244-254, out. 2011. Disponível em: <http://siaiap32.univali.br/seer/index.php/rc/article/view/2936>. Acesso em: 14 fev. 2017. 
SILVA, G. F. da. Multiculturalismo e educação intercultural: vertentes históricas e repercussões atuais na educação. In: FLEURI, R. M. (Org.). Educação intercultural: mediações necessárias. Rio de Janeiro: DP\&A, 2003. p. 17-52.

SILVA, K. A. O multiculturalismo e o currículo escolar: perspectivas e desafios para uma educação intercultural. 2014. 48f. Trabalho de Conclusão de Curso (Especialização em Fundamentos da Educação: Práticas Pedagógicas Interdisciplinares EAD) Universidade Estadual da Paraíba, Pró-Reitoria de Ensino Técnico, Médio e Educação a Distância.

SILVA, M. J. A. da; BRANDIM, M. R. L. Multiculturalismo e educação: em defesa da diversidade cultural. Diversa, ano I, n. 1, p. 51-66, jan.-jun. 2008.

SILVA, T. T. Currículo e identidade social: territórios contestados. In: (Org.). Alienígenas na sala de aula: uma introdução aos estudos culturais em educação. 3. ed. Petrópolis: Vozes, 1995. p. 190-207.

SODRÉ, M. A verdade seduzida. Rio de Janeiro: DP\&A, 2005.

SOUZA, J. F. de. Atualidade de Paulo Freire: contribuição ao debate sobre educação na diversidade cultural. São Paulo: Cortez, Instituto Paulo Freire, 2002.

UNESCO. Informe mundial. Investir na diversidade cultural e no diálogo intercultural. 2010. Disponível em: 〈http://www.ar.artbr/print/docs/diversidade.htm>. Acesso em: 12 jan. 2017.

Recebido em: 05/10/2017

Aprovado em: 22/01/2018 